\title{
Comparison of Long-Term Survival of Patients with BCLC Stage B Hepatocellular Carcinoma after Liver Resection or Transarterial Chemoembolization
}

\author{
Jian-Hong Zhong ${ }^{1 * 9}$, Bang-De Xiang ${ }^{19}$, Wen-Feng Gong ${ }^{1}$, Yang Ke ${ }^{1}$, Qin-Guo Mo ${ }^{1}$, Liang Ma ${ }^{1}, X_{i n g}$ Liu $^{1,2}$, \\ Le-Qun $\mathbf{L i}^{\mathbf{1}}{ }^{*}$
}

1 Hepatobiliary Surgery Department, Tumor Hospital of Guangxi Medical University, Nanning, People's Republic of China, 2 Gastrointestinal Surgery Department, the People's Hospital of Liuzhou, Liuzhou, People's Republic of China

\begin{abstract}
Background and Aims: Treatment of patients with Barcelona Clinic Liver Cancer Stage B hepatocellular carcinoma (BCLC-B $\mathrm{HCC}$ ) is controversial. This study compared the long-term survival of patients with BCLC-B HCC who received liver resection (LR) or transarterial chemoembolization (TACE).

Methods: A total of 257 and 135 BCLC-B HCC patients undergoing LR and TACE, respectively, were retrospectively evaluated. Kaplan-Meier method was used for long-term survival analysis. Independent prognostic predictors were determined by the Cox proportional hazards model.

Results: The hospital mortality rate was similar between groups ( $3.1 \%$ vs. $3.7 \% ; P=0.76)$. However, the LR group showed a significantly higher postoperative complication rate than the TACE group ( $28 \mathrm{vs.} 18.5 \% ; P=0.04$ ). At the same time, the LR group showed significantly higher overall survival rates (1 year, 84 vs. $69 \% ; 3$ years, 59 vs. 29\%; 5 years, 37 vs. $14 \%$; $P<0.001$ ). Moreover, similar results were observed in the propensity score model. Three independent prognostic factors were associated with worse overall survival: serum AFP level ( $\geq 400 \mathrm{ng} / \mathrm{ml})$, serum ALT level, and TACE.

Conclusions: LR appears to be as safe as TACE for patients with BCLC-B HCC, and it provides better long-term overall survival. However, prospective studies are needed to disclose if LR may be regarded as the preferred treatment for these patients as long as liver function is preserved.
\end{abstract}

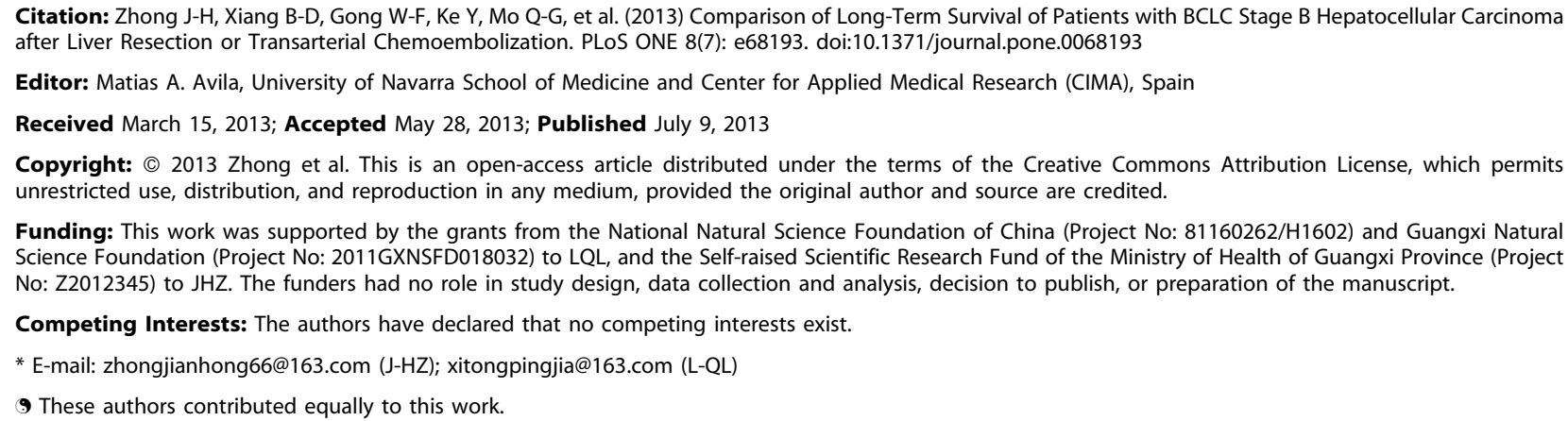

Copyright: (c) 2013 Zhong et al. This is an open-access article distributed under the terms of the Creative Commons Attribution License, which permits unrestricted use, distribution, and reproduction in any medium, provided the original author and source are credited.

Funding: This work was supported by the grants from the National Natural Science Foundation of China (Project No: 81160262/H1602) and Guangxi Natural Science Foundation (Project No: 2011GXNSFD018032) to LQL, and the Self-raised Scientific Research Fund of the Ministry of Health of Guangxi Province (Project No: Z2012345) to JHZ. The funders had no role in study design, data collection and analysis, decision to publish, or preparation of the manuscript.

Competing Interests: The authors have declared that no competing interests exist.

*E-mail: zhongjianhong66@163.com (J-HZ); xitongpingjia@163.com (L-QL)

9 These authors contributed equally to this work.

\section{Introduction}

Hepatocellular carcinoma (HCG) is associated with poor prognosis and its incidence is increasing in many countries [1,2]. Our understanding of HCC pathogenesis and progression has advanced, and so have diagnostic methods, surgical techniques, and perioperative care. However, the prognosis of HCC patients remains discouraging because of the high postoperative recurrence rate and high cancer mortality. Identifying the optimal therapy for HCC patients is therefore important for maximizing their longterm survival.

Treatment outcomes for HCC patients are affected by multiple variables, including tumor burden, the Child-Pugh score of liver function reserve and the performance status of the patient [3]. Several staging systems have been described for HCC, including the Barcelona Clinic Liver Cancer (BCLG) classification [4] and Okuda [5], CLIP [6], and French [7] scores. Only the BCLC staging system takes into account the above three variables. It links staging with treatment indications and prognostic information, such as estimated life expectancy [8]. Studies have validated and proposed the clinical usefulness of this staging system [4,9], making it one of the most reliable for HCG.

The BCLC intermediate stage, or stage B (BCLC-B), includes Child-Pugh A and B patients with large, single-focus HCC $(>5 \mathrm{~cm})$ and patients with multifocal HCG, defined as $>3$ tumors of any size, or 2-3 tumors with a maximal diameter $>3 \mathrm{~cm}$. To be categorized as BCLC-B, patients should be asymptomatic and have no vascular invasion or extrahepatic spread. The BCLC classification indicates that these patients are optimal candidates for transarterial chemoembolization (TACE) [4]. A systematic review of randomized clinical trials showed that TACE provided better 2-year survival than supportive treatment [10]. However, it is unclear whether TACE provides any long-term survival benefits. In addition, TACE has several potential disadvantages. Since the 
BCLC-B stage includes patients varying widely in tumor stage, hepatic function (Child-Pugh A or B) and disease etiology [11,12], TACE may not be the optimal therapy for all of them. The technique also requires certain equipment and skills that may be lacking in some countries, or it may not be the first choice of physicians because of local surgical priorities and practices [13].

Liver resection (LR) is a simpler and less expensive alternative to TACE that may be more suitable for some HCC patients. Studies in North America, Europe and Asia concur that LR can be safely performed in patients with large or multinodular HCG who have good liver function $[14,15,16,17,18]$. The 5-year survival rate has been reported to be about $37 \%$ [14]. However, the indication of liver resection (LR) for BCLC-B HCG remains controversial and should be assessed in more studies [11]. It may be that BCLC selection criteria for $\mathrm{LR}$ are too restrictive, and that $\mathrm{LR}$ is a safe and effective therapy for a larger proportion of HCC patients. The aim of this study was to assess the therapeutic value of $L R$ and compare it with TACE for treating BCLC-B HCG patients in southern China.

\section{Patients and Methods}

\section{Ethics Statement}

This study was approved by the institutional review board of Tumor Hospital of Guangxi Medical University. Written consent was given by the patients for their information to be stored in the hospital database and used for research.

\section{Patients}

Retrospective analysis was carried out on medical records of patients diagnosed with $\mathrm{HCC}$ who were included in a prospective database of the Tumor Hospital of Guangxi Medical University from January 2000 to November 2007. Patients who received their initial HCG treatment at other centers were excluded. We excluded patients who received only local ablation therapy, systematic chemotherapy, sorafenib therapy or supportive care. Patients in whom a malignancy other than HCC had been diagnosed within a 5-year period before the initial HCC treatment were also excluded. The remaining patients were treated with either LR or TAGE.

HCG diagnosis was confirmed after LR by histopathological examination of surgical samples in all patients. HCG diagnosis was confirmed in TACE patients by needle biopsy or by analysis of two images [ultrasonography, computed tomography (CT), or magnetic resonance imaging] in conjunction with a serum level of $\alpha$-fetoprotein (AFP) higher than $400 \mathrm{ng} / \mathrm{mL}$. Needle biopsy was performed in patients whose diagnosis based on imaging and AFP level was uncertain. Tumor status was assessed using various imaging techniques, including ultrasonography, CT scanning, magnetic resonance imaging, and/or hepatic angiography.

\section{Propensity Score Analysis}

In order to reduce the bias in patient selection, a propensity score analysis was developed to investigate causal relationships between treatments and outcomes in a retrospective study other than a randomized controlled trial [19]. Clinical variables entered in the propensity model were age, gender, tumor size, tumor number, serum bilirubin, ALT, albumin, and AFP. Subsequently, a one-to-one match between the LR and TACE groups was obtained by using the nearest-neighbor matching method [20].

\section{Liver Resection}

Only Child-Pugh A patients with BCLC-B disease were included in the current analysis. Indications for surgery were lack of ascites, hepatic encephalopathy, and hypersplenism, as well as the presence of appropriate residual liver volume, as determined by volumetric computed tomography [21]. Partial hepatectomy was performed following the techniques described by Zhou and coworkers [22]. The surgery started with a bilateral subcostal incision or L-shaped laparotomy with or without an upward midline extension. Intraoperative ultrasound was routinely performed to determine tumor location and assess the vascular anatomy of the liver. To minimize perioperative blood loss, Pringle's maneuver was carried out intermittently, each time for less than 20 minutes, with a clamp-free interval of $5 \mathrm{~min}$. The resection margin was more than $1 \mathrm{~cm}$. Adequate drainage was monitored.

\section{TACE Procedure}

Indications for using TACE for BCLC-B HCC patients were lack of ascites and main portal vein tumor thrombus, and presence of Child-Pugh A liver function. With the patient under local anesthesia, a 4F-to-5F French catheter was introduced into the abdominal aorta via the superficial femoral artery using the Seldinger technique. Hepatic arterial angiography was performed using fluoroscopy to guide the catheter into the celiac and superior mesenteric artery. Then the feeding arteries, tumor stain, and vascular anatomy surrounding the tumor were identified. A microcatheter was introduced through the catheter and directed to the feeding arteries. An emulsion of 5-15 ml lipiodol (Andre Guerbet, Aulnay-sous-Bois, France) and 5-fluorouracil (500 mg/ $\left.\mathrm{m}^{2}\right)$ with or without adriamycin $\left(30 \mathrm{mg} / \mathrm{m}^{2}\right)$ was infused into the feeding arteries until blood flow had nearly stopped. A follow-up CT scan was arranged one month later to evaluate the effect of TACE. The course was repeated once every $1-2$ months for $2-6$ cycles.

The default treatment for patients was liver resection; patients were given TACE only upon request.

\section{Patient Follow-up}

After surgery or TACE, all patients underwent regular followup involving a liver function test, measurement of serum AFP levels, abdominal ultrasonography, and chest radiography at an interval of 2-3 months in the first postoperative year and every 6 months in subsequent years. When intrahepatic recurrence was suspected, further investigation was carried out using CT and/or hepatic angiography. Chest CT or bone scans were conducted when distant metastasis was suspected. Biopsies were performed when necessary. Diagnoses of tumor recurrence and distant metastasis were based on cytohistology, or on the non-invasive diagnostic criteria for HCC used by the European Association for the Study of the Liver [23].

All recurrences and metastasis were evaluated for new treatment. Patients with recurrence were treated by hepatectomy, radiofrequency ablation therapy, microwave coagulation therapy, TACE, systemic chemotherapy, or sorafenib therapy. Therapy was decided based on extrahepatic disease, hepatic function, general health, and economic conditions.

\section{Study Endpoint}

The primary endpoint of the study was survival time after LR and TACE. The survival time was defined as the time between the date of surgery or TACE and the date of death. Patients who were alive at the end of follow-up were censored. 
Table 1. Preoperative clinicopathologic data of patients with Barcelona Clinic Liver Cancer stage B/Child-Pugh A hepatocellular carcinoma who received liver resection or transarterial chemoembolization (TACE).

\begin{tabular}{|c|c|c|c|}
\hline Variable & $\begin{array}{l}\text { Liver resection } \\
(\mathbf{n = 2 5 7 )}\end{array}$ & $\begin{array}{l}\text { TACE } \\
(n=135)\end{array}$ & $P$ value \\
\hline Age (yr) & $46.8 \pm 12.0$ & $48.7 \pm 12.5$ & 0.08 \\
\hline Gender (M/F) & $233(90.7 \%) / 24(9.3 \%)$ & $127(94.1 \%) / 8$ (5.9\%) & 0.24 \\
\hline Tumor size, $\mathrm{cm}$ & $8.9 \pm 3.0$ & $8.8 \pm 2.5$ & 0.63 \\
\hline Tumor number, S/M & 199 (77\%)/58 (23\%) & $104(77 \%) / 31(23 \%)$ & 0.93 \\
\hline Hepatitis B surface antigen & $243(94.6 \%) / 14(5.4 \%)$ & $130(90.4 \%) / 5$ (9.6\%) & 0.45 \\
\hline Hepatitis C antibody & $5(1.9 \%)$ & $3(2.2 \%)$ & 0.85 \\
\hline \multicolumn{4}{|l|}{$\alpha$-fetoprotein } \\
\hline$\geq 400 \mathrm{ng} / \mathrm{ml}$ & $143(55.6 \%)$ & $66(48.9 \%)$ & 0.20 \\
\hline$<400 \mathrm{ng} / \mathrm{ml}$ & $114(44.4 \%)$ & $69(51.1 \%)$ & \\
\hline Albumin (g/dl) & $3.9 \pm 5.6$ & $3.8 \pm 4.7$ & 0.07 \\
\hline Platelets $\left(10^{3} / \mu \mathrm{l}\right)$ & $193.4 \pm 74.9$ & $185.7 \pm 79.4$ & 0.34 \\
\hline Alanine aminotransferase (U/I) & $56.5 \pm 64.7$ & $62.4 \pm 45.5$ & 0.35 \\
\hline Total bilirubin (umol/L) & $14.5 \pm 5.3$ & $15.1 \pm 8.5$ & 0.40 \\
\hline Prothrombin time (s) & $13.1 \pm 1.2$ & $13.2 \pm 1.4$ & 0.53 \\
\hline \multicolumn{4}{|l|}{ Esophageal varices } \\
\hline Yes & $46(18 \%)$ & $30(22 \%)$ & 0.30 \\
\hline No & $211(82 \%)$ & $105(78 \%)$ & \\
\hline Hospital mortality & $8(3.1 \%)$ & $5(3.7 \%)$ & 0.76 \\
\hline Postoperative complications & $72(28.0 \%)$ & $25(18.5 \%)$ & 0.04 \\
\hline Median survival time (months) & $42.9 \pm 26.1$ & $21.0 \pm 18.8$ & $<0.01$ \\
\hline
\end{tabular}

Values with " \pm " are written as mean \pm SD.

Abbreviations: $\mathrm{S} / \mathrm{M}$, single tumor/multiple tumors.

doi:10.1371/journal.pone.0068193.t001

\section{Statistical Analysis}

Prior to this study, all demographic and clinicopathological data had been prospectively collected in a computer database. Differences between categorical data were analyzed using the chi-square test. Continuous data were expressed as mean \pm SD. Differences between continuous data were analyzed using the $t$ test. Survival analysis was calculated by the Kaplan-Meier method and group results were compared using the log-rank test. Multivariate analysis to identify independent prognostic factors was carried out using the Cox proportional hazards model to calculate the adjusted hazard ratio (HR) and 95\% confidence interval (CI). All statistical analyses were performed with SPSS (version 16.0, Chicago, IL, USA). For all tests, a $\mathrm{P}$ value $<0.05$ was considered statistically significant.

\section{Results}

\section{Study Population}

During the study period, 2,758 consecutive southern Chinese patients with HCG were enrolled in the database. Of these, 913 $(33.1 \%)$ were excluded because they had received their initial HCC treatment at other centers. Among the remaining 1,845 patients with complete survival data, 464 (25.1\%) had BCLC-B disease without extrahepatic metastasis. Of these, we excluded 57 patients $(12.3 \%)$ who received only local ablation therapy, systematic chemotherapy, sorafenib therapy or supportive care. Another 15 patients (3.2\%) were excluded because they had been diagnosed with a malignancy other than HCG within a 5-year period before receiving initial HCG treatment. The remaining 392 patients $(84.5 \%)$ were enrolled in the study.

Of these patients, 257 (65.6\%) received LR and $135(34.4 \%)$ received TACE. HCC diagnosis was confirmed after LR by histopathological examination of surgical samples. HCC diagnosis was confirmed in TACE patients by needle biopsy $(11.6 \%)$ or using two imaging techniques in conjunction with a serum level of $\alpha$-fetoprotein (AFP) higher than $400 \mathrm{ng} / \mathrm{mL}$ (88.4\%). Needle biopsy was performed in 13 patients for whom diagnosis based on imaging and AFP was uncertain.

\section{Clinicopathological Data}

Demographic and clinicopathological data for the 392 HCC patients are listed in Table 1. Most clinical characteristics were similar between the groups at baseline (Table 1). There were no significant differences in gender composition; tumor number; hepatitis incidence; levels of AFP, albumin, or alanine aminotransferase (ALT); prothrombin time; or hospital mortality. Patients in the TACE group were significantly older and had larger tumors and higher total serum bilirubin than those in the LR group. However, patients in the LR group had higher serum platelet counts, and they experienced more postoperative complications. The median age of all patients was $<50$ years. More than $90 \%$ of patients were male and $\mathrm{HB}$ Ag-positive. The proportion of hepatitis $\mathrm{C}$ virus infection was $2 \%$.

\section{Mortality and Morbidity}

The in-hospital mortality rate was similar in the LR group $(3.1 \%)$ and the TACE group $(3.7 \%)$. However, the postoperative 
Table 2. Postoperative complications in patients with Barcelona Clinic Liver Cancer stage B/Child-Pugh A hepatocellular carcinoma who received liver resection or transarterial chemoembolization.

\begin{tabular}{lll}
\hline & \multicolumn{2}{l}{ No. (\%) of patients } \\
\cline { 2 - 3 } Complication & $\begin{array}{l}\text { Liver resection } \\
\text { (n=257) }\end{array}$ & $\begin{array}{l}\text { TACE } \\
\text { (n= 135) }\end{array}$ \\
\hline Pulmonary infection & $18(7.0)$ & $4(3.0)$ \\
Liver function failure & $10(3.9)$ & $6(4.4)$ \\
Pleural effusion & $9(3.5)$ & $0(0)$ \\
Abdominal infection & $7(2.7)$ & $1(0.7)$ \\
Incision dehiscence & $6(2.3)$ & $0(0)$ \\
Gastrointestinal hemorrhage & $5(1.9)$ & $1(0.7)$ \\
Wound infection & $4(1.6)$ & $0(0)$ \\
Postoperative abdominal bleeding3 (1.2) & $0(0)$ \\
Deep venous thrombosis & $3(1.2)$ & $2(1.5)$ \\
Hepatic encephalopathy & $2(0.8)$ & $1(0.7)$ \\
Liver abscess & $2(0.8)$ & $0(0)$ \\
Intestinal obstruction & $2(0.8)$ & $0(0)$ \\
Pulmonary embolism & $1(0.4)$ & $1(0.7)$ \\
Puncture hematoma & $0(0)$ & $6(4.4)$ \\
Acute cholecystitis & $0(0)$ & $3(2.2)$ \\
Overall complications & $72(28)$ & $25(18.5)$ \\
\hline doi:10.1371/journal.pone.0068193.t002 &
\end{tabular}

complication rate was higher in the LR group (28\%) than in the TACE group $(18.5 \% ; \mathrm{P}=0.04)$. The most common complication of LR was pulmonary infection $(7 \%)$, while liver function failure $(4.4 \%)$ was the most common complication of TACE. The specific complications of the two group patients are listed in Table 2.

\section{Survival Analysis}

The overall survival rate was significantly better in the LR group than in the TACE group $(\mathrm{P}<0.05$; Fig. 1). During a mean follow-up period of $29 \pm 14$ months, 88 patients $(34 \%)$ in the LR group and 73 patients (54\%) in the TACE group died. The 1-, 3and 5-year overall survival rates of patients in the LR group were $84 \%, 59 \%$, and $37 \%$, while the corresponding rates in the TACE group were $69 \%, 29 \%$, and $14 \%(\mathrm{P}<0.001)$. Median survival time was 42.9 months in the LR group and 21.0 months in the TACE group $(\mathrm{P}<0.001)$.

Several factors linked to survival were taken into account in the survival analysis (Table 3). Univariate analysis showed that tumor size, serum ALT level, serum AFP level ( $\geq 400 \mathrm{ng} / \mathrm{ml}$ ), serum total bilirubin level, and treatment modalities were predictors of survival in the total study population. Multivariate analysis showed that serum AFP level $\geq 400 \mathrm{ng} / \mathrm{ml}(\mathrm{HR}=1.398,95 \%$ CI $1.071-$ $1.824, \mathrm{P}=0.014)$, serum ALT level $(\mathrm{HR}=1.003,95 \%$ CI $1.001-$ $1.005, \mathrm{P}=0.027)$, and treatment modalities $(\mathrm{HR}=2.149,95 \% \mathrm{CI}$ $1.592-2.902, \mathrm{P}<0.001$ ) were predictors of survival (Table 3 ).

\section{Survival Analysis of Patients with a Single Large Tumor}

The overall survival rate of patients with a single large tumor was significantly better in the LR group than in the TACE group $(\mathrm{P}<0.001$; Fig. 2). The 1-, 3- and 5-year overall survival rates of patients after LR were $87 \%, 65 \%$, and $41 \%$; the corresponding rates for patients after TACE were $69 \%, 30 \%$, and $18 \%$.

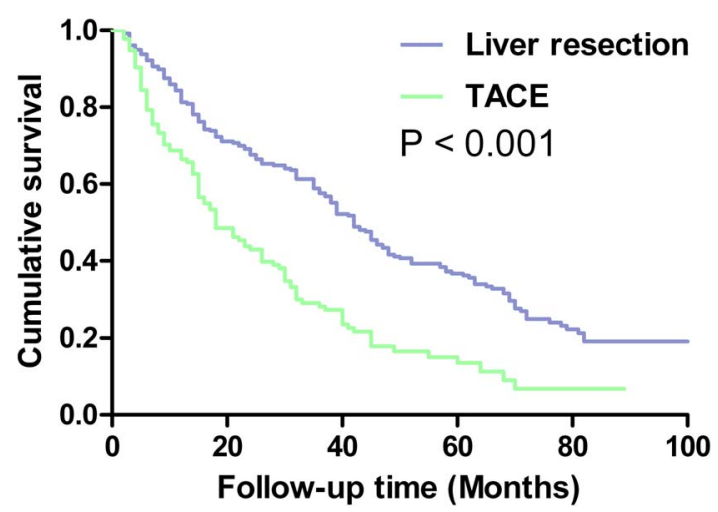

Figure 1. Overall survival curves of patients with BCLC-B HCC treated by liver resection or transarterial chemoembolization. doi:10.1371/journal.pone.0068193.g001

Table 3. Prognostic factors related to survival determined by univariate and multivariate analysis using the Cox proportional hazards model.

\begin{tabular}{|c|c|c|c|}
\hline & Hazard ratio & $95 \% \mathrm{Cl}$ & $P$ value \\
\hline \multicolumn{4}{|c|}{ Univariate analysis } \\
\hline Gender & 1.248 & $0.751-2.076$ & 0.393 \\
\hline Age & 0.993 & $0.982-1.004$ & 0.214 \\
\hline Tumor size & 1.084 & $1.038-1.138$ & $<0.001$ \\
\hline Tumor number & 0.800 & $0.549-1.164$ & 0.243 \\
\hline $\begin{array}{l}\text { Hepatitis B virus } \\
\text { infection }\end{array}$ & 0.966 & $0.526-1.774$ & 0.991 \\
\hline$\alpha$-fetoprotein & 1.426 & $1.098-1.851$ & 0.008 \\
\hline Albumin & 0.981 & $0.954-1.008$ & 0.172 \\
\hline Platelets & 0.999 & $0.998-1.001$ & 0.443 \\
\hline $\begin{array}{l}\text { Alanine } \\
\text { aminotransferase }\end{array}$ & 1.003 & $1.001-1.004$ & 0.002 \\
\hline Total bilirubin & 1.016 & $1.008-1.024$ & $<0.001$ \\
\hline Prothrombin time & 1.042 & $0.946-1.148$ & 0.404 \\
\hline Treatment modality & $y 2.431$ & $1.849-3.198$ & $<0.001$ \\
\hline \multicolumn{4}{|c|}{ Multivariate analysis } \\
\hline Tumor size & 1.029 & $0.981-1.079$ & 0.245 \\
\hline$\alpha$-fetoprotein & 1.398 & $1.071-1.824$ & 0.014 \\
\hline $\begin{array}{l}\text { Alanine } \\
\text { aminotransferase }\end{array}$ & 1.003 & $1.001-1.005$ & 0.027 \\
\hline Total bilirubin & 1.009 & 0.999-1.019 & 0.064 \\
\hline Treatment modality & $y 2.149$ & $1.592-2.902$ & $<0.001$ \\
\hline
\end{tabular}

doi:10.1371/journal.pone.0068193.t003

\section{Survival Analysis of Patients with Multiple Tumors}

The 1-, 3-, and 5-year overall survival rates for patients with multiple tumors were significantly better in the LR group $(76 \%$, $39 \%$, and $24 \%$ ) than in the TACE group $(68 \%, 25 \%$, and $4 \%)$ $(\mathrm{P}=0.036$; Fig. 3$)$.

\section{Survival Analysis with Propensity Score}

Subsequently, for minimize the confounding factors, propensity score analysis with one-to-one nearest neighbor matching method was applied, including age, gender, tumor size and number, serum bilirubin, ALT, albumin, and AFP. Sixty-one pair patients were 


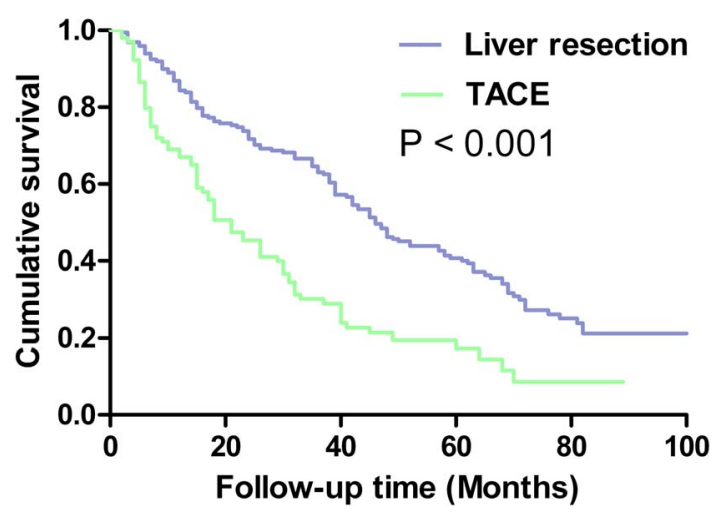

Figure 2. Overall survival curves of patients with a single large tumor of BCLC-B HCC treated by liver resection or transarterial chemoembolization.

doi:10.1371/journal.pone.0068193.g002

matched in each group. The above eight factors appeared to be well matched between groups. After matching, the overall survival rates of the LR group were also superior to that of the TACE group, with $87 \%$ vs. $77 \%, 62 \%$ vs. $44 \%$, and $35 \%$ vs. $20 \%$, respectively, for the 1-, 3- and 5-year overall survival rates $(\mathrm{P}=0.025$, Fig. 4).

\section{Discussion}

This study shows that LR can offer better overall survival than TACE for selected BCLC-B HCG patients, and that both techniques offer acceptable morbidity and similar in-hospital mortality. Since large tumor size $[24,25,26]$ and multiple nodules $[25,26,27]$ are independent risk factors of recurrence and mortality [28], we analyzed overall survival for patients with large tumor size or multiple nodules independently. Results showed that LR can still offer better overall survival than TACE in both types of patients.

Our results in total population and propensity model analysis are consistent with recent reports that LR offers the best survival benefit for patients with BCLC-B HCC $[14,15,24,27,29,30,31,32,33,34,35]$. Therefore, large tumor size and multiple tumors should not exclude patients from LR. This surgery has also been shown to provide better quality of life than TACE for HCG patients [36].

The BCLC classification system has traditionally been used to guide treatment selection for patients with BCLC-B HCC. However, this system may not always provide the most appropriate recommendation. Surgical resection is the only hope for BCLG-B and -G HCG patients, but the BCLG classification considers these patients unsuitable for LR [37]. In recent decades, with advances in surgical techniques and preoperative preparation, the indications for LR have expanded. It is now considered a safe and routine surgical procedure and there is no absolute contraindication for it.

The BCLC staging classification recommends TACE as essentially the only option for patients with BCLC-B HCG and for some patients with BCLC-C HCC [4]. However, the BCLC-B stage includes a heterogeneous population of $\mathrm{HCC}$ patients, which means that not all patients will derive the same survival benefits from TACE [11]. In fact, the lack of a standard treatment methodology and patient selection criteria for TACE has made it difficult to draw any firm conclusions about the efficacy of the procedure for BCLC-B and -C HCG patients [11]. In addition, TACE can lead to drug resistance in some patients [38].

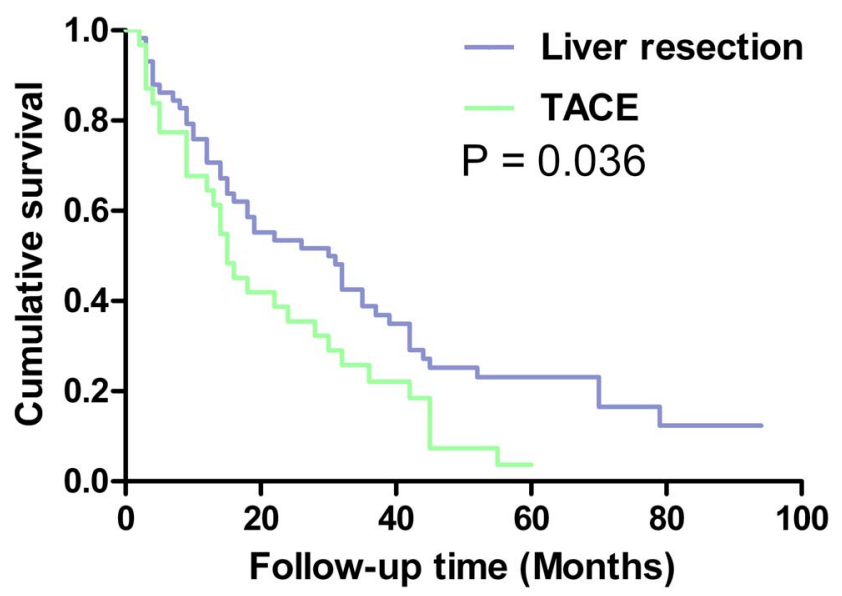

Figure 3. Overall survival curves of patients with multiple tumors of BCLC-B HCC treated by liver resection or transarterial chemoembolization.

doi:10.1371/journal.pone.0068193.g003

In order to compare the efficacy of LR for BCLC-B and C HCG reported by other recent studies, we address a comprehensive literature review on the subject (Table 4) $[14,15,16,24,27,29,31,32,33,34,39,40,41,42,43,44,45,46]$. Our results show LR to offer better survival rates than TACE in the shorter and longer term ( 1 year, 84 vs. $69 \% ; 3$ years, 59 vs. $29 \% ; 5$ years, 37 vs. $14 \% ; \mathrm{P}<0.001)$. This is similar to a 3 -year survival rate of $30 \%$ after TACE reported in other studies [24,29]. In contrast, for patients with BCLG-B HCG who underwent LR, the median survival was 28 to 60 months, 3-year overall survival was $37-72 \%$, and 5-year overall survival was $32-60 \%$. Even for patients with BCLC-C HCC, the 5-year overall survival was more than $10 \%$ (Table 4). Actually, the recent study with large sample size by Torzilli and coworkers [46] collecting data from 10 centers showed that LR is in current practice widely. For patients with limited disease, there are no restrictions on tumor size, number or macrovascular invasion. Therefore, the BCLC selection criteria for LR seem too restrictive and should be expanded so that it can be considered a treatment option for patients with BCLC-B and C HCG.

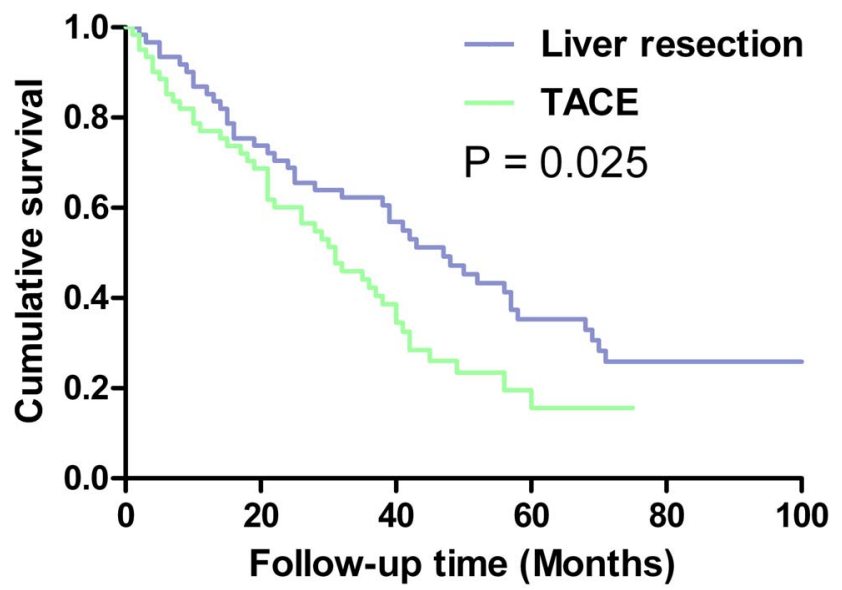

Figure 4. Overall survival curves of patients with BCLC-B HCC treated by liver resection or transarterial chemoembolization after propensity score.

doi:10.1371/journal.pone.0068193.g004 
Table 4. Outcomes of liver resection for patients with BCLC-B or -C hepatocellular carcinoma in the recent literature (with sample size $>50$ and published between 2005 and 2013).

\begin{tabular}{|c|c|c|c|c|c|c|}
\hline \multirow[t]{2}{*}{ Study } & \multirow[t]{2}{*}{ Country } & \multirow[t]{2}{*}{$\begin{array}{l}\text { No. of } \\
\text { patients }\end{array}$} & \multirow[t]{2}{*}{ Disease characteristics } & \multirow[t]{2}{*}{$\begin{array}{l}\text { Median overall } \\
\text { survival (mon) }\end{array}$} & \multicolumn{2}{|c|}{ Overall survival (\%) } \\
\hline & & & & & 3-year & 5-year \\
\hline This study & Southern China & 257 & BCLC-B HCC & 43 & 59 & 37 \\
\hline Chang 2012 [39] & Taiwan & 478 & BCLC-B and C HCC & - & 52 & 41 \\
\hline Cheng 2012 [40] & Taiwan & 104 & Tumor size $>5 \mathrm{~cm}$ & - & - & About 60 \\
\hline Cho 2007 [41] & South Korea & 61 & Tumor size: $5 \sim 10$ & - & 59 & 53 \\
\hline Delis 2010 [42] & Greece & 66 & Tumor size $>5 \mathrm{~cm}$ & 36 & 37 & 32 \\
\hline Ho 2009 [15] & Taiwan & 122 & BCLC-B HCC & 42 & 52 & 37 \\
\hline Hsu 2012 [24] & Taiwan & 268 & $\mathrm{BCLC}-\mathrm{B} / \mathrm{C} / \mathrm{D} \mathrm{HCC}$ & - & 63 & 43 \\
\hline Huang 2012 [43] & Taiwan & 139 & $\begin{array}{l}\text { Tumor size }>10 \mathrm{~cm} \text { or adjacent organ } \\
\text { invasion, or ruptured tumor }\end{array}$ & 20 & 39 & 29 \\
\hline Ishizawa 2008 [16] & Japan & 126 & $\begin{array}{l}\text { Multiple HCC with or without portal } \\
\text { hypertention }\end{array}$ & - & 72 & 58 \\
\hline Liau 2005 [44] & USA & 82 & Tumor size $\geq 10 \mathrm{~cm}$ & 32 & 48 & 33 \\
\hline Lin 2010 [27] & Taiwan & 93 & BCLC-B HCC & 28 & 49 & - \\
\hline $\mathrm{Ng} 2005$ [31] & Asia, Europe and the USA & 380 & BCLC-B HCC & 37 & 50 & 39 \\
\hline Ruzzenente 2009 [14] & Italy & 105 & $\begin{array}{l}\text { Tumor size }>5 \mathrm{~cm} \text { with or without } \\
\text { multinodular }\end{array}$ & 14 & - & 16 \\
\hline Pawlik 2005 [33] & Asia, Europe and the USA & 300 & $\mathrm{HCC} \geq 10 \mathrm{~cm}$ & 20 & 37 & 27 \\
\hline Pawlik 2005 [34] & Asia, Europe and the USA & 102 & BCLC-C HCC & 11 & 17 & 10 \\
\hline \multirow[t]{2}{*}{ Torzilli 2013 [46] } & $\begin{array}{l}\text { Eastern \& Western } \\
\text { Experiences }\end{array}$ & 663 & BCLC-B HCC & - & 71 & 57 \\
\hline & & 274 & BCLC-C HCC & - & 49 & 38 \\
\hline Wang 2008 [29] & Taiwan & 243 & BCLC-B HCC & 60 & 64 & 51 \\
\hline Yamashita 2011 [32] & Japan & 53 & $\mathrm{HCC} \geq 10 \mathrm{~cm}$ & - & 43 & 35 \\
\hline Yang 2012 [45] & Eastern China & 511 & BCLC-C HCC & 28 & 41 & 31 \\
\hline
\end{tabular}

doi:10.1371/journal.pone.0068193.t004

Our results, obtained with a population in southern China, are similar to those reported in studies in other Asian populations. Our data showed 3- and 5-year overall survival of LR patients of $59 \%$ and $37 \%$, with a median survival time of 43 months. These results are similar to those reported by Wang and coworkers [29] for patients in Taiwan. In another study conducted in Taiwan, overall survival for patients with $\geq 2$ tumors was higher after LR than after TACE [15]. A study by Hsu et al. [24] in Taiwan compared the efficacy of LR and TACE for patients with HCG beyond the Milan criteria. This study concluded that LR is as safe as TACE and provides better long-term survival for HCC patients beyond the Milan criteria [24]. In a retrospective study very similar to ours, Lin et al. [27] included 171 patients in Taiwan with BCLCB/Child-Pugh A HCC. Those authors also found LR to be as safe as TACE and to provide better survival rates. The 3-year overall survival was $49 \%$ for the LR group and $2 \%$ for the TACE group $(\mathrm{P}<0.001)$ [27]. Taken together, these studies argue for considering LR as the preferred treatment for patients with BCLC-B HCG.

Several studies have examined prognostic factors for survival of BCLC-B HCG patients after LR [15,24,27,31]. These studies reported different risk factors linked to long-term survival. Generally speaking, patients with no risk factors are predicted to have the best prognosis, while patients with three or more risk factors are predicted to have the worst overall survival [31]. In the present study, tumor size, ALT, AFP $(\geq 400 \mathrm{ng} / \mathrm{ml})$, total bilirubin, and TACE were associated with worse overall survival.
However, on multivariate analysis, only AFP ( $\geq 400 \mathrm{ng} / \mathrm{ml})$, ALT, and TACE were independent predictors of overall survival. Another study [47] also found AFP level to be an independent predictor of mortality in hepatitis G-related HCC. Though a few recent studies $[48,49]$ proposed that preoperative AFP levels are not useful for predicting postoperative survival of patients with early-stage HCC, AFP is used as a biomarker of HCC diagnosis [50] and has even proven useful as a marker for predicting antitumor response after radiofrequency ablation [51] and sorafenib therapy [52].

Like AFP, serum ALT was a predictor of survival in our BCLCB HCG patients. This may reflect the fact that more than $90 \%$ of our HCG patients were HBV carriers; in such patients, long-term change in serum ALT is an independent predictor of risk for HCC [53]. At the same time, ALT is a widely used indicator of liver function and serum ALT level is associated with the degree of inflammation in liver disease [54]. Thus we may have detected ALT as a survival predictor because HCC patients with long-term $\mathrm{HBV}$ infection have worse prognosis.

There are several potential limitations of this study. First, most of our patients were males younger than 50 with chronic HBV infection. Therefore, the results may not be representative of all HCC patients. Second, this is a retrospective study, so there may have been selection bias. Nevertheless, all the patients in this study were admitted consecutively into our hospital for treatment. Moreover, the results from the propensity score analysis were similar to that from the overall population. Third, our results 
showing the superior results of LR compared to TACE should be used with discretion, since when tumor recurrence occurs or is likely, other therapies such as sorafenib, TACE or conservative treatment should be adopted.

In conclusion, LR yielded better overall survival than TACE in patients with BCLC-B HCG. For BCLC-B HCG patients with preserved liver function, LR may be considered the preferred treatment. However, prospective studies with large sample size are needed to reassess the efficacy of LR for these patients.

\section{References}

1. Siegel R, Ward E, Brawley O, Jemal A (2011) Cancer statistics, 2011: the impact of eliminating socioeconomic and racial disparities on premature cancer deaths. CA Cancer J Clin 61: 212-236.

2. Bosetti C, Levi F, Boffetta P, Lucchini F, Negri E, et al. (2008) Trends in mortality from hepatocellular carcinoma in Europe, 1980-2004. Hepatology 48: $137-145$.

3. Lencioni R, Chen XP, Dagher L, Venook AP (2010) Treatment of intermediate/advanced hepatocellular carcinoma in the clinic: how can outcomes be improved? Oncologist 15 Suppl 4: 42-52.

4. Bruix J, Sherman M (2011) Management of hepatocellular carcinoma: an update. Hepatology 53: 1020-1022.

5. Okuda K, Ohtsuki T, Obata H, Tomimatsu M, Okazaki N, et al. (1985) Natural history of hepatocellular carcinoma and prognosis in relation to treatment. Study of 850 patients. Cancer 56: 918-928.

6. (1998) A new prognostic system for hepatocellular carcinoma: a retrospective study of 435 patients: the Cancer of the Liver Italian Program (CLIP) investigators. Hepatology 28: 751-755.

7. Chevret S, Trinchet JC, Mathieu D, Rached AA, Beaugrand M, et al. (1999) A new prognostic classification for predicting survival in patients with hepatocellular carcinoma. Groupe d'Etude et de Traitement du Carcinome Hepatocellulaire. J Hepatol 31: 133-141.

8. Rhim H, Lim HK, Choi D (2010) Current status of radiofrequency ablation of hepatocellular carcinoma. World J Gastrointest Surg 2: 128-136.

9. Cillo U, Vitale A, Grigoletto F, Farinati F, Brolese A, et al. (2006) Prospective validation of the Barcelona Clinic Liver Cancer staging system. J Hepatol 44: 723-731.

10. Llovet JM, Bruix J (2003) Systematic review of randomized trials for unresectable hepatocellular carcinoma: Chemoembolization improves survival. Hepatology 37: 429-442.

11. Raoul JL, Sangro B, Forner A, Mazzaferro V, Piscaglia F, et al. (2011) Evolving strategies for the management of intermediate-stage hepatocellular carcinoma: available evidence and expert opinion on the use of transarterial chemoembolization. Cancer Treat Rev 37: 212-220.

12. Llovet JM, Di Bisceglie AM, Bruix J, Kramer BS, Lencioni R, et al. (2008) Design and endpoints of clinical trials in hepatocellular carcinoma. J Natl Cancer Inst 100: 698-711.

13. Kim SE, Lee HC, Kim KM, Lim YS, Chung YH, et al. (2011) Applicability of the BCLC staging system to patients with hepatocellular carcinoma in Korea: analysis at a single center with a liver transplant center. Korean J Hepatol 17: 113-119.

14. Ruzzenente A, Capra F, Pachera S, Iacono C, Piccirillo G, et al. (2009) Is liver resection justified in advanced hepatocellular carcinoma? Results of an observational study in 464 patients. J Gastrointest Surg 13: 1313-1320.

15. Ho MC, Huang GT, Tsang YM, Lee PH, Chen DS, et al. (2009) Liver resection improves the survival of patients with multiple hepatocellular carcinomas. Ann Surg Oncol 16: 848-855.

16. Ishizawa T, Hasegawa K, Aoki T, Takahashi M, Inoue Y, et al. (2008) Neither multiple tumors nor portal hypertension are surgical contraindications for hepatocellular carcinoma. Gastroenterology 134: 1908-1916.

17. Torzilli G, Donadon M, Marconi M, Palmisano A, Del Fabbro D, et al. (2008) Hepatectomy for stage B and stage C hepatocellular carcinoma in the Barcelona Clinic Liver Cancer classification: results of a prospective analysis. Arch Surg 143: 1082-1090.

18. Vitale A, Saracino E, Boccagni P, Brolese A, D'Amico F, et al. (2009) Validation of the BCLC prognostic system in surgical hepatocellular cancer patients. Transplant Proc 41: 1260-1263.

19. D'Agostino RB, Jr. (1998) Propensity score methods for bias reduction in the comparison of a treatment to a non-randomized control group. Stat Med 17: 2265-2281.

20. Hung HH, Chiou YY, Hsia CY, Su CW, Chou YH, et al. (2011) Survival rates are comparable after radiofrequency ablation or surgery in patients with small hepatocellular carcinomas. Clin Gastroenterol Hepatol 9: 79-86.

21. Hsieh CB, Yu CY, Tzao C, Chu HC, Chen TW, et al. (2006) Prediction of the risk of hepatic failure in patients with portal vein invasion hepatoma after hepatic resection. Eur J Surg Oncol 32: 72-76.

22. Zhou XD, Tang ZY, Yang BH, Lin ZY, Ma ZC, et al. (2001) Experience of 1000 patients who underwent hepatectomy for small hepatocellular carcinoma. Cancer 91: 1479-1486.

\section{Acknowledgments}

The authors thank Armando Chapin Rodríguez, PhD for his language editing, which substantially improved the quality of the manuscript.

\section{Author Contributions}

Conceived and designed the experiments: J-HZ L-QL. Performed the experiments: W-FG YK Q-GM B-DX. Analyzed the data: F-XW LM XL. Contributed reagents/materials/analysis tools: J-HZ. Wrote the paper: J$\mathrm{HZ}$.

23. Bruix J, Sherman M, Llovet JM, Beaugrand M, Lencioni R, et al. (2001) Clinical management of hepatocellular carcinoma. Conclusions of the Barcelona-2000 EASL conference. European Association for the Study of the Liver. J Hepatol 35: 421-430.

24. Hsu CY, Hsia GY, Huang YH, Su CW, Lin HC, et al. (2012) Comparison of surgical resection and transarterial chemoembolization for hepatocellular carcinoma beyond the Milan criteria: a propensity score analysis. Ann Surg Oncol 19: 842-849.

25. Shah SA, Cleary SP, Wei AC, Yang I, Taylor BR, et al. (2007) Recurrence after liver resection for hepatocellular carcinoma: risk factors, treatment, and outcomes. Surgery 141: 330-339.

26. Kaibori M, Saito T, Matsui Y, Uchida Y, Ishizaki M, et al. (2007) A review of the prognostic factors in patients with recurrence after liver resection for hepatocellular carcinoma. Am J Surg 193: 431-437.

27. Lin CT, Hsu KF, Chen TW, Yu JC, Chan DC, et al. (2010) Comparing hepatic resection and transarterial chemoembolization for Barcelona Clinic Liver Cancer (BCLC) stage B hepatocellular carcinoma: change for treatment of choice? World Journal of Surgery 34: 2155-2161.

28. Rahbari NN, Mehrabi A, Mollberg NM, Muller SA, Koch M, et al. (2011) Hepatocellular carcinoma: current management and perspectives for the future. Ann Surg 253: 453-469.

29. Wang JH, Changchien CS, Hu TH, Lee CM, Kee KM, et al. (2008) The efficacy of treatment schedules according to Barcelona Clinic Liver Cancer staging for hepatocellular carcinoma - Survival analysis of 3892 patients. Eur J Cancer 44: 1000-1006.

30. Abdalla EK, Denys A, Hasegawa K, Leung TW, Makuuchi M, et al. (2008) Treatment of large and advanced hepatocellular carcinoma. Ann Surg Oncol 15: 979-985.

31. Ng KK, Vauthey JN, Pawlik TM, Lauwers GY, Regimbeau JM, et al. (2005) Is hepatic resection for large or multinodular hepatocellular carcinoma justified? Results from a multi-institutional database. Ann Surg Oncol 12: 364-373.

32. Yamashita Y, Taketomi A, Shirabe K, Aishima S, Tsuijita E, et al (2011) Outcomes of hepatic resection for huge hepatocellular carcinoma $(>/=10 \mathrm{~cm}$ in diameter). J Surg Oncol 104: 292-298.

33. Pawlik TM, Poon RT, Abdalla EK, Zorzi D, Ikai I, et al. (2005) Critical appraisal of the clinical and pathologic predictors of survival after resection of large hepatocellular carcinoma. Arch Surg 140: 450-457; discussion 457-458.

34. Pawlik TM, Poon RT, Abdalla EK, Ikai I, Nagorney DM, et al, (2005) Hepatectomy for hepatocellular carcinoma with major portal or hepatic vein invasion: results of a multicenter study. Surgery 137: 403-410.

35. Le Treut YP, Hardwigsen J, Ananian P, Saisse J, Gregoire E, et al. (2006) Resection of hepatocellular carcinoma with tumor thrombus in the major vasculature. A European case-control series. J Gastrointest Surg 10: 855-862.

36. Toro A, Pulvirenti E, Palermo F, Di Carlo I (2012) Health-related quality of life in patients with hepatocellular carcinoma after hepatic resection, transcatheter arterial chemoembolization, radiofrequency ablation or no treatment. Surg Oncol 21: e23-30.

37. Forner A, Llovet JM, Bruix J (2012) Hepatocellular carcinoma. Lancet 379: $1245-1255$.

38. Forner A, Reig ME, de Lope CR, Bruix J (2010) Current strategy for staging and treatment: the BCLC update and future prospects. Semin Liver Dis 30: 61-74.

39. Chang WT, Kao WY, Chau GY, Su CW, Lei HJ, et al. (2012) Hepatic resection can provide long-term survival of patients with non-early-stage hepatocellular carcinoma: extending the indication for resection? Surgery 152: 809-820.

40. Cheng CH, Yu MC, Wu TH, Lee CF, Chan KM, et al. (2012) Surgical resection of centrally located large hepatocellular carcinoma. Chang Gung Med J 35: $178-191$.

41. Cho YB, Lee KU, Lee HW, Cho EH, Yang SH, et al. (2007) Outcomes of hepatic resection for a single large hepatocellular carcinoma. World Journal of Surgery 31: 795-801.

42. Delis SG, Bakoyiannis A, Tassopoulos N, Athanassiou K, Kelekis D, et al. (2010) Hepatic resection for hepatocellular carcinoma exceeding Milan criteria. Surg Oncol 19: 200-207.

43. Huang JF, Wu SM, Wu TH, Lee CF, Wu TJ, et al. (2012) Liver resection for complicated hepatocellular carcinoma: challenges but opportunity for long-term survivals. J Surg Oncol 106: 959-965. 
44. Liau KH, Ruo L, Shia J, Padela A, Gonen M, et al. (2005) Outcome of partial hepatectomy for large $(>10 \mathrm{~cm})$ hepatocellular carcinoma. Cancer 104: 19481955.

45. Yang T, Lin C, Zhai J, Shi S, Zhu M, et al. (2012) Surgical resection for advanced hepatocellular carcinoma according to Barcelona Clinic Liver Cancer (BCLC) staging. J Cancer Res Clin Oncol 138: 1121-1129.

46. Torzilli G, Belghiti J, Kokudo N, Takayama T, Capussotti L, et al. (2013) A Snapshot of the Effective Indications and Results of Surgery for Hepatocellular Carcinoma in Tertiary Referral Centers: Is It Adherent to the EASL/AASLD Recommendations?: An Observational Study of the HCC East-West Study Group. Ann Surg 257: 929-937.

47. Tyson GL, Duan Z, Kramer JR, Davila JA, Richardson PA, et al. (2011) Level of alpha-fetoprotein predicts mortality among patients with hepatitis C-related hepatocellular carcinoma. Clin Gastroenterol Hepatol 9: 989-994.

48. Shim JH, Yoon DL, Han S, Lee YJ, Lee SG, et al. (2012) Is serum alphafetoprotein useful for predicting recurrence and mortality specific to hepatocellular carcinoma after hepatectomy? A test based on propensity scores and competing risks analysis. Ann Surg Oncol 19: 3687-3696.

49. Giannini EG, Marenco S, Borgonovo G, Savarino V, Farinati F, et al. (2012) Alpha-fetoprotein has no prognostic role in small hepatocellular carcinoma identified during surveillance in compensated cirrhosis. Hepatology 56: 13711379 .

50. Bertino G, Neri S, Bruno GM, Ardiri AM, Calvagno GS, et al. (2011) Diagnostic and prognostic value of alpha-fetoprotein, des-gamma-carboxy prothrombin and squamous cell carcinoma antigen immunoglobulin $\mathrm{M}$ complexes in hepatocellular carcinoma. Minerva Med 102: 363-371.

51. Kao WY, Chiou YY, Hung HH, Su CW, Chou YH, et al. (2012) Serum alphafetoprotein response can predict prognosis in hepatocellular carcinoma patients undergoing radiofrequency ablation therapy. Clin Radiol 67: 429-436.

52. Kuzuya T, Asahina Y, Tsuchiya K, Tanaka K, Suzuki Y, et al. (2011) Early decrease in alpha-fetoprotein, but not des-gamma-carboxy prothrombin, predicts sorafenib efficacy in patients with advanced hepatocellular carcinoma. Oncology 81: 251-258

53. Chen CF, Lee WC, Yang HI, Chang HC, Jen CL, et al. (2011) Changes in serum levels of HBV DNA and alanine aminotransferase determine risk for hepatocellular carcinoma. Gastroenterology 141: 1240-1248, 1248 e1241-1242.

54. Maeda T, Shimada M, Harimoto N, Tsujita E, Aishima S, et al. (2008) Prognosis of early hepatocellular carcinoma after hepatic resection. Hepatogastroenterology 55: 1428-1432. 